\title{
The ancestor worship practices' evolutions in Peri- Urban Vietnam a case of study in ho chi minh city
}

\begin{abstract}
Peri-urban areas, with their landscapes of mixed rural and urban activities, represent a form of urbanization that puts the traditional urban-rural duality in question. The peri-urban area of Ho Chi Minh City is approached in our paper according to the local context taking into account the theoretical stakes posed by this socio-geographical phenomenon. This paper identifies three types of settlement in the peri-urban area of our study. They are characterized by their different practices of ancestor worship, a traditional culture in Vietnam. The analysis of the new modes of practice this culture in the context of transition makes it possible to understand the changes which affect the social relation and the evolution of the role of the women.
\end{abstract}

Keywords: Viêtnam, ho chi minh city, peri urbanization, transition, ancestor worship, culture, geography
Volume 2 Issue 2 - 2017

\author{
Thu Trang NGO,' Antoine Wallet ${ }^{2}$ \\ 'University of Social Sciences and Humanities,Vietnam National \\ University Ho Chi Minh City,Vietnam \\ ${ }^{2}$ Graduate intern at University of Social Sciences and \\ Humanities, Vietnam National University Ho Chi Minh City, \\ Vietnam
}

Correspondence: Thu Trang Ngo, University of Social Sciences and Humanities,Vietnam National University Ho Chi Minh City, Vietnam, Email ngothutrang1980@gmail.com

Received: October 26, 2017 | Published: November 16, 2017

\section{Introduction}

Ancestor worship is not a particular religion, it is more a cultural fact and a social practice that crosses the different religious currents and may even involve individuals and families, not claiming religious affiliation. ${ }^{1}$ However, ancestor worship is considered as the most fundamental ritual act in Viet Nam. ${ }^{2}$ Most Vietnamese have practiced this domestic cult since the dawn of time. Each person is in two families, "hai họ", including the paternal line, "họ nội" and the maternal line, "họ ngoại". In the strict tradition, ancestor worship for a given individual concerns only the paternal lineage. That's why boys play an important role in honoring them. In the family, if there are boys and girls, it is the boys who will organize the anniversary of the death of the ancestors. It is significant that "nội" and "ngoại" translated respectively inside and outside. Recall that the particular feeling that connects everything is filial piety, "hiếu". The girls in the family are "externals" and the boys are "internals". This thought is still strong in country life but has changed in urban life.

This ritual takes place on different temporalities. It usually consists of offering flowers, incense or fruits to ancestor by placing them on the ancestors' altar day-to-day (Figure 1). On special occasions such as the first, second fifth and tenth anniversary of (patrilineal) ancestor's death (ngày giỗ), a bigger ceremony is organized. During these specials events, the family at large and neighbours are invited. This practice contributes to the production of strong social networks, by connecting places of birth and places of death. It honours not only the family ancestors on a regular basis, but it also stresses and reaffirms the family's links with the so-called "ancestor land" (quê nhà/đất hương hỏa).

With the recent urbanization of the outskirts of the cities and intensification of migration, the production of such networks faces new challenges, but continues to adapt. Indeed, the peri-urban area is undergoing major changes: enlargement of the urban space and shrinking of the rural area, establishment of new infrastructures and increase of the density of buildings and of the rural exodus, intensity of the circulation merchandise. ${ }^{3}$ Peri-urban areas, with their landscapes of mixed rural and urban activities ${ }^{4}$ present a form of urbanization that puts the traditional urban-rural duality in question.
The peri-urbanization of metropolises in developing countries has accompanied territorial and social segregation and a deterioration of the built and natural environment ${ }^{5}$ Moreover, because urbanization is rapid and of great magnitude, the peri-urban area poses environmental problems, with economic, demographic and political questions, which affect what passes from an anthropological and socio-geographical point of view. ${ }^{6,7}$ All of these elements play a role in defining the goals of sustainable development in large cities. ${ }^{8}$ This ultimately comes down to a better consideration of social aspects, not just economic and environmental. ${ }^{9}$

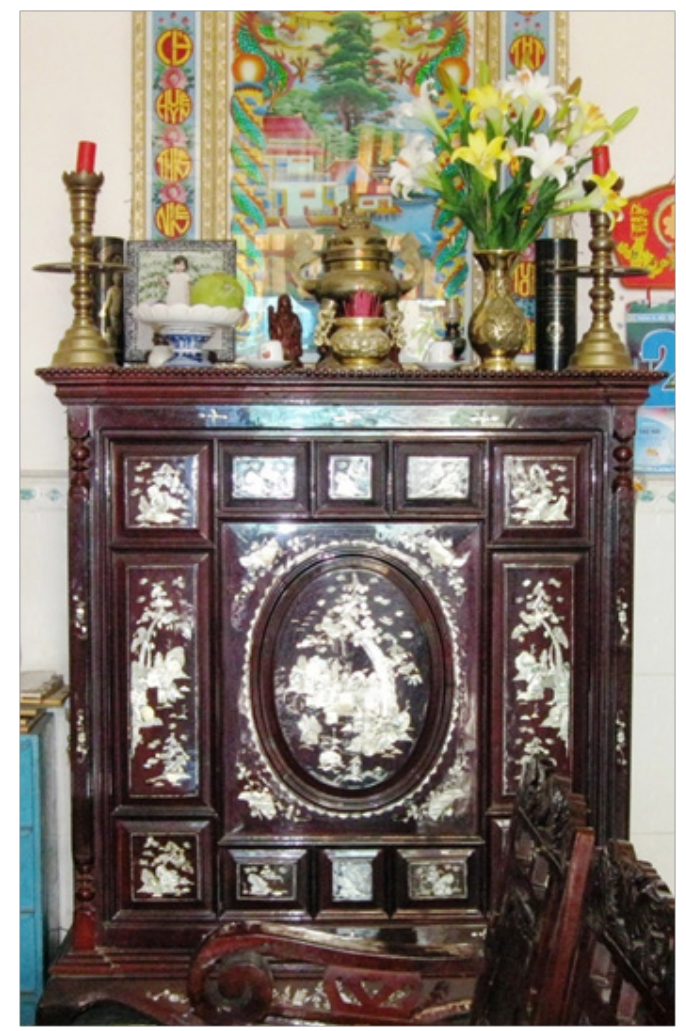

Figure I An ancestors' altar. 
Peri-urbanization in Vietnam is indicative of what is happening in other countries of South-East Asia. In this part of the world, this phenomenon is characterized by the growth of megacities. In Vietnam, the rural population generates an important rural environment and the peri-urban border appears as a transitional space between the city and the countryside, ${ }^{10}$ associated with modernity and tradition. In these areas there are two types of newcomers, on the one hand, people from the countryside who are seeking employment in the city where they bring their traditional practices of rural areas. On the other hand, people who work in the city center who takes advantages from the cheaper land price and live in individual buildings. They are new owners who develop projects of construction and life of their own. They belong to the middle-class, highly concerned with modernity ", but they approach it relatively "closed" in that they fall back on themselves and do not show interest in communicating with others.

More traditional in their conceptions and ways of life, the former inhabitants, who did not have to move, remain beside their relatives or their neighbors. Taking advantage of the process of peri-urbanization, they build on their free land and rent rooms. Tenants are therefore in an undeveloped space. Each type of settlement necessarily favors a different way of living peri-urban space in the megacities of Vietnam. They constitute a very revealing ground of the interactions between the countryside and the city, between tradition and modernity. These are the three types of settlement that we will consider in our study to see how and to what extent they combine with the emergence of new behaviors on the practice of the ancestor worship. Due to the fast growth of Ho Chi Minh City during the last few decades, the peri-urban areas of Ho Chi Minh City are the scenes of numerous evolutions and adaptations made by the people who now live there. They now have to adapt their ancestor worship practices according to their new settlement. Thus they invent new ways to practice their traditional practices in an urban context.

\section{Materials and methods}

Peri-urbanization is a pretty loose concept that is mostly defined as the urbanization of cities outskirts. These fringes are then called peri-urban areas and become "peri-urban interface". ${ }^{11}$ Thus, periurban areas are in-transition spaces as they move from fully rural areas to developed urban areas. ${ }^{12}$ Peri-urban area are also uneasy to define for their inhabitants, Eric Harms use the concept of symbolic opposites in order to understand the opposition between rural and urban. The latter are similar to the categories of inside and outside. ${ }^{13}$ This phenomenon leads to create fringe surrounding the urban core. It modifies the landscape as it brings new forms of space occupations, new activities such as industry on former agricultural lands. Indeed, in 1991, Terry McGee indentifies the land use in peri-urban as a mix between agricultural activities and new industrial activities and develops the concept of desakota (from the Indonesian desa: village and kota: town) to describe the peri-urban areas form in South-East Asia. ${ }^{4}$ Thus, the peri-urban areas are subject to many conflicts for land use as peri-urbanization leads to the loss of agricultral lands in profits of industry. ${ }^{14}$ This development also transforms the transport infrastructure and the demographic structure of these areas: it is interesting to observe the consumption of space at the expense of agricultural land, construction, the establishment of infrastructure, immigration also well from the city center than from the rural area, the mobility of the population, urban transport, professional mobility, etc. ${ }^{15}$ Michael Leaf sees the peri-urban as a border zone. Peri-urban areas are those where urban growth occurs, where road networks develop, where buildings are built, where low-density housing is spread and small areas of rural land exist. From this space emerges the interaction of the economy, society and the environment: The periurbanization to indicate the coming together and intermixing of the urban and the rural, implying the potential for the emergence of wholly new forms of social, economic and environmental interaction that are no longer accommodated by these received categories $\gg{ }^{16}$ These authors note that the peri-urban zone is characterized by the equipment of the infrastructure system and the density of construction, Gubry emphasizing the issue of migration, transport, urban poverty and occupational mobility. But the authors rarely address the meeting of urban and rural populations in this space, which implies the possibility of seeing new forms of social, economic and environmental organization, which would not be included in the categories. As Clark notices, the peri-urban areas are a mix of both rural and urban compound, Urban structure, urban culture, urban lifestyles are mixing, at times quite intensely, with rural structure, rural culture and rural lifestyles. This intense mixture of urban. One of the unique preconditions of peri-urban areas in Southeast Asia is the dense road and canal system. ${ }^{17}$ This study aims to better understand the numerous social and economic changes taking place in peri-urban areas. Through the study of the social practices of the inhabitants of a space, we wish to make a shift and replace the "daily practices" at the center of the analysis of peri-urbanization.

Ho Chi Minh City is the most populated city of Viet Nam. In June 2017 the Statistical Office of Ho Chi Minh City estimated its population at 8224000 inhabitants, more than in the capital, Ha Noi (7 230000 inhabitants). Ho Chi Minh City is composed of 24 districts. Following the administrative denomination there are two types of under-provincial districts: rural districts (huyện) and urban districts (quận). As a municipality of provincial level, Ho Chi Minh City is divided in five huyện and nineteen quận. As shown in the underneath map (Figure 2) there are currently thirteen intra-urban districts (intraurban space and old cores), six peri-urban districts (quận ven, periurban area) and five rural districts (rural area). Created from the Bình Chánh rural district division in 2003, Bình Tân is now the most recent urban district of Ho Chi Minh City. It is the interface rounding between Ho Chi Minh Cityand the Mekong Delta regions. Located to the west of the central districts of Ho Chi Minh City, it has important infrastructures such as the national road $1 \mathrm{~A}$ and the bus station of the west (bến xe miền tây). Over the last ten years this district has a significant industrial development which brings a significant number of immigrants from areas south of Ho Chi Minh City. As such, the population of this district has increased by approximately $60 \%$ between 2004 and 2017 (with a current population of approximately 686474 inhabitants). Thus, this rapid growth leads to numerous changes in the housing development of the district. Once mainly inhabited by rural families who owned typical low-rise detached houses with small gardens (nhà vườn), Bình Tân district today welcomes numerous new housing developments, mainly dedicated to the urban middleclass. In addition, the migrant workers attracted by the industrial zones are often moving to collective dormitories or rent individual rooms within existing homes. This phenomenon leads to create a "suburban society" in the making. The new owners, from the middle class and coming from the city center or the provinces, live in a space created by the promoters' projects. Native people live in formerly structured spaces. Migrant workers live in a "spontaneous", undeveloped space, because the former owners spontaneously build rooms for rent in their free lands according to the demand for rental housing. In consequences, Bình Tân district perfectly illustrates the numerous mutations and fast development of Ho Chi Minh City. 


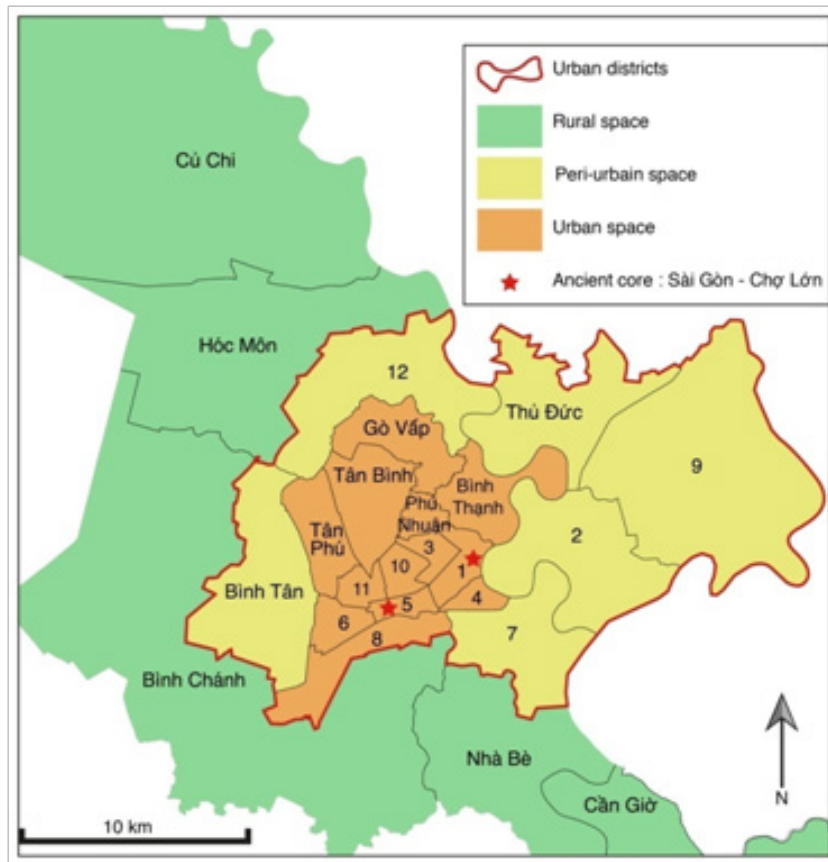

Figure 2 The administrative map of the urban spaces of Ho Chi Minh City.

To answer that question, the authors developed a qualitative approach as well as a quantitative one. This specific study of ancestor worshipping evolutions is based on a larger survey conducted between 2011, 2012 and 2016 in Bình Tân district. Since the census data do not allow us to address this type of questioning, we used a survey carried out in the three types of settlement selected using questionnaires completed in situ and addressing 304 people from the borough (one hundred per settlement type)

We conducted a pre-survey to detail the themes and fix the samples. It was made from spontaneous conversations in the studied space. The first concern was to develop the most effective sampling possible taking into account the constraints of the field and the availability of populations, a two-week stay was necessary to make a first round of the ten neighborhoods of the borough Bình Tân. Questionnaires were conducted in all neighborhoods of this district, but for frequent observation and multiple semi-directive interviews, only the precise neighborhood of Binh Tri Đong B was chosen. It is a neighborhood where there are more small restaurants, more spontaneous markets than others and it presents a strong and rapid urbanization process. Above all, this area clearly presents the three types of habitats that interest our research and is strongly affected by the rapid transformation of the rural space to the urban space.In this neighborhood, there are large numbers of projects and unused free land. The area of public land of the city for Bình Tân district is located only in the study area.In addition, the Binh Tri Đong B neighborhood is well known for its developed areas for new owners like Ten Lua and $\mathrm{Da} \mathrm{Xa}$. This neighborhood is home to many tenants who rent rooms in a space where they mix with the former owners.

For each type of settlement, this is a stratified random sample based on socio-demographic characteristics of men and women and broad age categories (young / adult / elderly). It is distributed on the basis of the ten wards that compose the district. This sample, without pretending to be of an exact representativeness of the prevailing situation, allows an exploratory study. People were interviewed in Vietnamese in each neighborhood, no questionnaire being administered in a street where another would have been. The sample thus includes 182 women and 122 men. During that period, 45 semi directive interviews have been leaded. Our questions have privileged, on the one hand, representations concerning ancestor worship and on the other hand, practices corresponding to major issues of social anthropological relations.

\section{Results and discussion}

\section{From rural to urban, living in the peri-urban ho chi minh city}

As mentioned above, peri-urban areas are transitional spaces from rural to urban. Thus, the social structure of the Bình Tân District evolved. The Ho Chi Minh City growth leaded to an important urban sprawl with its flow of inhabitants seeking building spaces outside the city center and investors, buying land at low cost and waiting for a resale with a strong added value. This phenomenon was reinforced in the case of the Bình Tân District district when it was reclassified as an urban district. Indeed, the latter comes with subsidies to build, to carry out investment projects and equip itself with infrastructure. This is the cause of the growing group of inhabitants and the increase in the price of land. The former inhabitants having to accept the projects of construction, they sell their right of use of the land to the persons in charge of the projects of investment and live now in a limited space. The spontaneous urbanization of HCM-City has established multifaceted peri-urban areas, where the infrastructure is not sufficient in view of the increase in the number of inhabitants (narrow roads, water discharge system, waste treatment ...) where locals run small informal businesses and where they mostly use motorbike to move.

Nevertheless, the urbanization of this urban-fringe has created a development of Bình Tân's technical and social infrastructure, with a concentration of means: priority is given to works of public interest in health, education and communication channels. The cultural, artistic, informative and sensitizing activities were developed by the Bình Tân District's authorities with the aim of promoting a healthy and civic life in the population. Emphasis was placed on raising awareness of Party policies, legal guidelines and regulations, as well as on the organization of traditional festivals, Lunar New Year and so on. The quality and quantity of programs are gradually being improved, responding to the needs and aspirations of the population in cultural works. However, the complex still faces many difficulties for lack of sufficient funding. Urbanization has also impacted critical infrastructure such as education and health systems. Thus the number of classes, the number of beds in hospitals or medical clinics has increased since the beginning of the 21 st century. ${ }^{18}$

The arrival of new populations from urban centers also encourages the emergence of new social practices at the heart of this area in transition. The first is the appearance of commuters who live in periurban areas but continue to work in more central districts. New forms of consumption are emerging and in 2016 the Aeon Mall was opened. These malls represent real figures of modernity in Asia and in particular in Vietnam where people come to wander and enjoy the fresh air. ${ }^{19}$ In this context of transition, new forms of living are emerging. Vertical apartment towers develop in opposition to the horizontal architecture that has long been prevalent in Ho Chi Minh City. To these new forms are added the mutations of the already built habitat. In the case of Bình Tân District, this is the informal extension of the traditional rural house in order to meet the rental demand experiencing strong growth due to the arrival of migrants attracted by industries. 
The peri-urban area brings together groups of inhabitants of various origins. They live in different types of habitats (old and new owners, tenants). They contribute to modernity by adapting themselves to the transformations of their environment but are burdened by socioeconomic and environmental risks.

\section{The ancestor worship in rural and urban areas}

As mentioned above, peri-urban and rural areas are very different. Therefore, the same practice, here ancestor worship, can be achieved in different ways while keeping or not its significance within the family home. This study tends to show that the practices evolved, not on their ordinary days, but on peculiar time such as the death anniversary. Different factors can explain this evolution. The place needed to organize such ceremonies with the family and the neighbors is not always available in the urban and peri-urban areas. Ms. Cam, tenants who live in Bình Tân District confirms by sharing her experience of death anniversary in rural areas: "There are always a lot of people at parties in the countryside. Just with the relatives of the family, we are already very numerous. Every time I come back to attend my mother's birthday, I find that my mother-in-law has to prepare a lot of dishes. I tell my dad that we should not have a big party. We must simplify things. My mother-in-law tells me that we have only one party to organize every year, we have to prepare it well, to party well."

As well as the space, the time needful to organize and hold the ceremony is an important criterion for the modalities of this practice. Ms. Thuy Nga an active tenant, shares her experience: "When we were in the country, every time we had a birthday of one of the dead of my husband's family, it was very tiring because we had to invite relatives, neighbors and prepare the party 2 days before. On those days, it was sometimes necessary to watch until the night to make the cakes, to prepare the chickens, the ducks to make people eat. Here, I do not worship ancestors." Obviously, Mrs. Thuy Nga finds the situation much more advantageous in Bình Tân District because the ceremony is less tiring as she was charged to prepare all the dishes when she was living in a rural area. Thus, peri-urban space is a place of transition where the ceremony is organized more and more simply for the reason that people have neither the time nor the space nor the money to organize it. Most families do not invite neighbors because they are afraid to embarrass them. According to Ms. Dau, who is a new owner senior: "I usually worship the anniversary of my husband's death and my parents-in-laws' anniversary. However, next year, I will organize these celebrations together on one single day and I am not sure I will invite a lot of people. My children are too busy to help and so are my neighbors. Here it is not like in the countryside; if we do a celebration party, it will disturb the neighbors."

Ms. Dau will bring together the birthday party of all the family's dead. It becomes a practical question. It shows us that this system of relationships does no longer exist in the urban areas and can even annoy its neighbors as itself. But most importantly, the main idea of change in worship comes from the fact that people no longer have enough room to celebrate with all the neighbors and also no longer have the land to produce the food needed for the invitation.

Neighborhood relations are no longer the same. Only the families of tenants practice this worship in the traditional way, but often by returning to the campaign at the time of the death anniversary. In the urban space, even they simply organize or practice this worship, or even the daily worship in the family.As the narrow tube-houses do not have courtyard or garden and the inhabitants don't have access to the legal permits required to make use of the public spaces, death anniversary ceremonies are organized inside of the house, thus celebrated with a reduced number of guests.

\section{The ancestor worship by settlement type in Bình Tân District}

As shown before, it is possible to find three type of settlement in Bình Tân District: the new owners that live houses built according to the building regulations in place and located in the developed areas of the study area, the tenants that rent rooms in the undeveloped space, mixing with the former owners and the former owners have lived in this neighborhood for a long time. They show changes in their living space and habits to adapt to other ways of living.

One of the main results of this study and the type of habitat strongly influences the methods of realization of the ancestor's worship. Respondents' responses showed changes in worship practices. The new owners proceed in a rather modern way ( $83 \%$ of the new owners describe the same practices), by simplifying the party and not inviting the neighbors or all the relatives. This trend is also present among the former owners (38.9\% of this group of inhabitants). $46.3 \%$ of these have an intermediate position between tradition and modernity in the practice of ancestor worship.

In the peri-urban areas, fewer homeowner households are keeping traditional practices. However, there is a different trend among tenants in urban areas (Table 1). Only $33.3 \%$ of renters chose to simplify the practice of ancestor worship: they are often elderly tenants who have no family in the countryside to carry out this cult. They practice this worship alone in their rented room. For $59.8 \%$ of tenants, the practice is traditional but they rely on their family remained in the countryside. It is the rural families of the tenants who organize this worship by inviting neighbors and bringing together all the family members, including those who are urban tenants and who move at the time of major ceremony.

As Table 1 shows, the mode of ancestor worship depends on the type of inhabitants. In the study area, it can be noted that tenants are interested in celebrating ancestor worship in the countryside. Most of the former owners practice ancestor worship intermediary, they still keep some rituals but they are mostly reluctant to invite their neighbors as it could be in the countryside (46.3\%). Death anniversary parties are organized more simply than before $(38.9 \%)$, with the invitation of few neighbors. It is an intermediate way to practice of worship. Mr. Long is a former owner; a senior who still keeps the tradition in his way of life describes it well: "We chose the altar of ancestors. It's very important because it's a family custom. Every year, we must organize the anniversary of the death of the ancestors but the way of organizing the party does not look like the one organized in the countryside: there are not many guests at home. The parties are organized so the children do not forget the family custom ". From now on, the anniversary of the dead is the occasion by which family members gather and where children think of their ancestors.

In the new owner settlement type, the ceremony only includes family members. The new owners tend to simplify the practice of ancestor worship (83.0\%): they do not invite relatives and they celebrate on weekends and not on the exact date of the anniversary of the death of the ancestor, as Ms. Tam, an active new owner, explains: "it's the anniversary of the death of my parents-in-law, it's important but we organize it very simply, we do not invite relatives or 
neighbors". Ms. Tam thinks that this ceremony is still important, but its organization is simplified. Thus, ancestral worship is still important in Vietnamese families who live in peri-urban areas; only $7.6 \%$ of Table I The ancestors worship practices according to the type of settlement the sample does not practice the ancestor worship. Nonetheless, as this study shows, the practice of worship differs strongly between different types of settlement.

\begin{tabular}{lllll}
\hline Settlement type/death anniversary & Ancient owners & Tenants & New owners & Total \\
\hline Traditional (as before) & $8.30 \%$ & $59.80 \%$ & $0.00 \%$ & $23.00 \%$ \\
Intermediate & $46.30 \%$ & $3.90 \%$ & $3.20 \%$ & $18.8 \%$ \\
Modern (simply) & $38.90 \%$ & $33.30 \%$ & $83.00 \%$ & $50.70 \%$ \\
No practice & $6.50 \%$ & $2.90 \%$ & $13.80 \%$ & $7.60 \%$ \\
Total & $100 \%$ & $100 \%$ & $100 \%$ & $100 \%$ \\
\hline
\end{tabular}

\section{The new place of women in the worship organization}

In Vietnamese society of the past, personally caring for worship meant being a priority in the heritage of family land. However, until today, the Vietnamese remain deeply attached to a model of patriarchal family, which is considered as an ideal institution that guarantees well-being and continuity in the sense of the "Confucian model". ${ }^{20}$ It dictates family morality in terms of duties and obligations: they become the supreme values for its members. They therefore always express family piety in ancestor worship. These rites have a profound influence on daily existence. The eldest son (in northern Vietnam) or the youngest son (in southern Vietnam) in the Vietnamese family was usually ancestral worshipers and therefore had the right to inherit the land from his ancestors. Nowadays, in the peri-urban areas, this cult has changed a lot: the role of women and men becomes more egalitarian, the woman participating in the practice. However, it remains to be seen whether there is a trend towards equality in the practice of ancestor worship between women and men in order to understand how inheritances work today. This change, observed in respondents' responses, would mean that currently the right of inheritance is the same between family members.

To illustrate our point, the interview of Ms. Trinh, seems to be relevant as it shows the new situation of equality between men and women in the practice of worship. She is a senior landowner that lives in Bình Tân district and is responsible if the ancestors' worship in her family. Ms. Trinh has had success in her professional life and is therefore in a good position in society. Now retired she participates in neighborhood associations, monitors rooms for rent, takes care of vegetable garden or communicates with neighbors. She wants to elevate the role of the woman in the family and she tries it in different ways. As she is aware about the place of women in Vietnamese society is smaller than the men's place. She often expresses to her brothers her desire for equality between men and women in the family "I am a woman but my brothers listen to me". This act frequently leads to conflicts: "We often argue over belongings that our parents left us. Everything is due to the fact that my brothers do not want to share equitably and justly." This also concerns the organization of the altar of ancestors. In the Vietnamese context, if sons are more involved in worship, there is nothing to prevent girls from doing so too: "Ancestral cults must be done normally by men. But I think that in worship we are all the same: men as women. For example, I practice the worship of my parents at home." Even if Ms. Trinh is single and doesn't have to experiences conflicts with a potential husband, who could claim the right to practice the worship, she succeeded in changing the behavior of her brothers. They now accept that she takes care of the ancestor worship rituals. Thus, this example shows the evolutions underway on the role of women in the practice of ancestor worship in peri-urban areas.

\section{Conclusion}

This study identifies three elements in the evolution of the ancient worship practices in the peri-urban areas. The worship practices are more traditional in the rural area and they are in transition in the peri-urban area. Information obtained during the interviews showed us different changes in the organization of ceremonies related to ancestor worships in the peri-urban. Even if changes exist on a daily basis, most of the changes appear during uncommon periods such as death anniversary. The organization of a single worship day for all the family ancestors has become a matter of convenience and appropriate social behavior in an urban context. In the latter, the lack of place forces the inhabitants to simplify the death anniversary ceremonies.

In peri-urban areas, settlement directly influences the methods of realization of ancestor worship. The ancient owners simplify the holidays but they invite a few neighbors close to the anniversary of the dead. They have an intermediate behavior between a certain traditional and a more modern conception of the worship practice. The new owners simplify the practice by inviting only the close family or they group the birthdays of their dead on one or two days a year. Tenants, most of whom live in cramped rented rooms, do not practice ancestor worship, but return to the countryside to do so with their family in a traditional way. Moreover, living in a peri-urban context tends to disconnect the people from their "ancestor land". As the tenants live far from their hometown, theirs practices are limited to ceremonies organized by the family on the ancestor land, in rural areas. It is important to notice that women now participate in worship. They practice ancestor worship, a sign of equality between man and woman in the heritage of the land of ancestors.

The effects of peri-urbanization and the modernization of rural areas can therefore be seen on many scales. At the city or borough level, there is the appearance of new infrastructures, for example. At home, daily practices are changing. The inhabitants are not only a "victim" of peri-urbanization, but adapt to their changing environment. They thus become actors in peri-urbanization and modernization in the same way as public authorities or investors.

\section{Acknowledgements}

None.

\section{Conflicts of interest}

Authors declares that there is no conflict of interest. 


\section{References}

1. Rouault NF. Le culte des ancêtres dans la famille vietnamienne. Hommes et migrations. 2001;1232:26-33.

2. Jellema K. Everywhere Incense Burning: Remembering Ancestors in Đổi Mói Vietnam. Journal of Southeast Asian Studies. 2007;38(3):467-492.

3. Gee MT. Revisiting the urban fringe: Reassessing the challenges of the Mega-Urbanization process in Southeast Asia. Trends of urbanization in Southeast Asia, Centre d'Etude d'urbaine et de Développement, Vietnam. 2008. p. 21-52.

4. Gee MT. The emergence of Desakota regions in Asia: Expanding a hypothesis. In: Ginsberg N, et al. editor. The extended metropolis: Settlement transition in Asia. University of Hawaii press, Hawaii, USA; 1991. p. 3-25.

5. Bassand M. Métropolisation et inégalités sociales. Presses polytechnique et universitaire romande. 1997;14(33):57-58.

6. Parenteau R. Habitat et environnement urbain au Viêt-nam. Karthala: Canada; 1997. p. 334.

7. Gubry P. Niveau de vie et déplacement dans les métropoles vietnamiennes: HCM-Ville et Hanoi. Revue Tiers Monde. 2010;201:107-129.

8. Bolay JC, Cartoux S, Cunha A, et al. Sustainable development and urban growth: Precarious habitat and water management in Hô Chi Minh City, Viêt-nam. Habitat International. 1997;21(2):185-197.

9. Bailly A. Développement social durable des villes. Economica. Switzerland; 2000. p. 170.

10. Dao TT. Urbanization and periurbanization in Hanoi. Trends of urbanization and suburbanization in Southeast Asia, Centre d'Etude d'urbaine et de Développement. Vietnam. 2008. p. 21-52.
11. Gregor M, Simon D, Thompson D. The peri-urban interface: Approaches to sustainable natural and human resource use. Developing Areas Research Group : London; 2006.

12. Hudalah D, Winarso H, Woltjer J. Peri-urbanisation in East Asia: A new challenge for planning? International Development Planning Review. 2007;29:503-519.

13. Harms E. Saigon's edge: On the margins of Ho Chi Minh City. University of Minnesota Press. 2011;64(1):294.

14. Ravetz J, Fertner C, Nielsen TS. The dynamics of peri-urbanization. Peri-urban futures: Scenarios and models for land use change in Europe. Springer Berlin Heidelberg, USA; 2013. p. 13-14.

15. Gubry P. Urbanization in Southeast Asia. Research ideas from the experience of Viêt-nam. Trends of urbanization in Southeast Asia, Centre d'Etude d'urbaine et de Développement (CEFURDS), Vietnam. 2008. p. $107-129$.

16. Leaf M. New urban frontiers: Periurbanization and territorialization in southeast Asia. Trends of urbanization in Southeast Asia, Centre d'Etude d'urbaine et de Développement (CEFURDS), Vietnam. 2008. p. 141-167.

17. Clark J. Peri-Urban Agglomerations in Southeast Asia. Exurban Change Project White Paper. 2006. p. 17.

18. Ngo TTT. La modernité dans l'espace périurbain à Ho Chi Minh Ville. Cas d'étude: l'arrondissement Binh Tân, $\mathrm{PhD}$ Thesis in Geography, University of Pau and Pays de l'Adour, France; 2014.

19. Peyvel E, Gibert M. Đi chơi đi ! Allons-nous amuser. Entre public et privé, une approche socio-spatiale des pratiques de loisirs à Hồ Chí Minh Ville. EchoGéo. 2012;21.

20. Tran V. Nho giáo và văn hóa Việtnam (Confucianism and Vietnamese culture). Nxb Văn hóa dân tộc, Vietnam. 2000. p. 501-515. 